Volume 4 No 2 Maret 2019

p-ISSN : 2460-8750 e-ISSN : 2615-1731

http://dx.doi.org/10.26858/talenta.v4i2.8486

\title{
EFFECTS OF FLEXIBLE WORK ARRANGEMENTS ON ETHICAL DECISION MAKING: JOB SATISFACTION AS A MEDIATOR
}

\author{
Tiara Veronika Simamora ${ }^{1}$, Martina Dwi Mustika ${ }^{2}$, Bertina Sjabadhyni $^{3}$ \\ Fakultas Psikologi Universitas Indonesia \\ Email: ${ }^{1}$ Simamora03@gmail.com ${ }^{2}$ Martinadwimustika@gmail.com ${ }^{3}$ berti@ui.ac.id
}

(C)2018 -JPT Fakultas Psikologi Universitas Negeri Makassar. Ini adalah artikel dengan

akses terbuka di bawah licenci CC BY-NC-4.0 (https://creativecommons.org/licenses/by-nc/4.0/ ).

\begin{abstract}
Abstrack. Ethical Decision Making (EDM) is behavior that is based on cognitive morals to choose an ethical decision. Flexible Work Arrangement (FWA) is a work option that allows employees to be flexible in terms of the place of work and its settlement. Job satisfaction is a positive feeling about work. This study will see job satisfaction mediates flexible work arrangement relationships with ethical decision making. This research method is a survey with a cross sectional design. The sample in this study were those who had worked in Indonesia with simple random sampling. The results of the study point out a significant indirect effect of flexible work arrangement on ethical decision making through job satisfaction.
\end{abstract}

Keywords : Ethical Decision Making, Flexibel Work Arrangement, and Job Satisfaction

\begin{abstract}
Abstrak. Ethical Decision Making (EDM) ialah perilaku yang berdasarkan pada moral kognitif untuk memilih sebuah keputusan etis. FWA merupakan sebuah pilihan kerja yang memungkinkan karyawan fleksibil dalam hal tempat pekerjaan dan penyelesaiannya. Kepuasaan kerja adalah perasaan positif tentang pekerjaan. Penelitian ini akan melihat apakah kepuasan kerja memediasi hubungan flexible work arrangement dengan ethical decision making" Metode penelitian ialah survey dengan desain cross sectional. Sampel dalam penelitian ini adalah mereka yang telah bekerja di Indonesia dengan pengambilan sampel secara acak (simple random sampling). Hasil dari penelitian menunjukkan efek tidak langsung yang signifikan flexible work arrangement terhadap ethical decicion making melalui kepuasaan kerja
\end{abstract}

Kata Kunci: Pengambilan Keputusan Etis, Flesibilitas kerja, dan Kepuasaan kerja

\section{PENDAHULUAN}

Direksi PT Pertamina Hulu Energi (PHE) diduga mengambil keputusan untuk mengambil alih ROC Oil Ltd, dalam menggarap Blok BMG tanpa didukung feasibility study atau kajian kelayakan hingga tahap final due dilligence (kajian lengkap mutakhir) dan juga tanpa persetujuan Dewan Komisaris (Sukmana,
2018). Hal ini berdampak pada kerugian keuangan negara dari Pertamina sebesar 31 juta dollar AS dan 26 juta dollar AS atau setara Rp 568 miliar. Kejadian ini menunjukkan adanya dilema moral yang mungkin dihadapi oleh anggota organisasi di tempat kerja. Pengambilan keputusan seperti ini memiliki dampak yang luar biasa pada tingkat perilaku etis dalam organisasi, 
yang menjadi perhatian utama para pemimpin organisasi, pejabat negara, dan masyarakat pada umumnya. Untuk meningkatkan perilaku etis, penting untuk memahami beberapa faktor yang mempengaruh seperti faktor individu, situasional, dan terkait masalah yang memengaruhi keputusan individu tentang dilema moral. Oleh karena itu, proses pengambilan keputusan etis (Ethical Decision Making - EDM) adalah bidang yang sangat menarik untuk diteliti lebih lanjut.

\section{Ethical Decision Making (EDM)} ialah perilaku yang berdasarkan pada moral kognitif untuk memilih sebuah keputusan etis (benar-salah, hak, tugas, dan kewajiban) yang secara moral sesuai dengan masyarakat (Jones, 1991; Kohlberg, 1969). Beberapa faktor yang memengaruhi pengambilan keputusan etis adalah faktor individu (kebangsaan, agama, jenis kelamin, umur, pendidikan, sikap, nilai pekerjaan, dan kepribadian) dan situasi organisasi (Barnett, 2001). Faktor situasional disini dapat membantu menjelaskan dan memprediksi perilaku pengambilan keputusan etis individu dalam organisasi. Kekuatan pengaruh ini mungkin terjadi akibat variabel situasi yang timbul dari konteks pekerjaan itu sendiri, misalnya saja tren fleksibilitas kerja yang saat ini mulai dilakukan di beberapa start up di Indonesia.
Fleksibilitas kerja (Flexible Work Arrangement - FWA) di Indonesia biasanya dilakukan oleh karyawan industri kreatif, seperti media, agensi periklanan, lembaga survei pasar, hingga biro jasa desain dan arsitektur (Duhita, 2018). FWA didefinisikan sebagai pilihan kerja yang memungkinkan fleksibilitas dalam hal tempat pekerjaan diselesaikan (telecommuting/flexplace) serta waktu pekerjaan selesai (flextime) (Rau \& Hyland, 2002). FWA lebih berfokus pada pekerjaan selesai, daripada memikirkan bagaimana, dimana ataupun kapan pekerjaan itu selesai. FWA dilandasi oleh Teori Konservasi Sumber Daya (Hobfoll, 1989) dimana mengintegrasikan model stres sebagai suatu kerangka alternatif untuk memahami konflik pekerjaan dan keluarga. Individu akan berusaha untuk mendapatkan dan melindungi sumber daya pribadi dan sosial yang dimilikinya. Sumber daya yang dimaksud meliputi sasaran, kondisi (status pernikahan, jabatan), karakter pribadi (nilai diri), dan energi (waktu, uang, pengetahuan). FWA muncul sebagai solusi dari ancaman terhadap kehilangan ketiga sumber daya tersebut yang akan mengakibatkan "keadaan negatif”, misalnya mengalami stres, ketidakpuasan kerja, depresi atau tekanan.

Penelitian menunjukkan bahwa FWA dapat meningkatkan motivasi dan kepuasan kerja, membantu karyawan 
memiliki tingkat energi yang lebih tinggi pada pekerjaan karena dapat menghilangkan waktu yang terbuang (Annel \& Hartmann, 2007). FWA juga dapat mengurangi stres, meningkatkan kesejahteraan karyawan yang akan meningkatkan produktivitas karyawan dalam bekerja (Ongori, 2007). Beberapa artikel menyebutkan bahwa telecommuting memberi keuntungan untuk karyawan contohnya ongkos bepergian yang lebih murah serta pengurangan biaya untuk sewa ruangan. Goden dan Veiga (2005) menjelaskan telecommuting memudahkan karyawan untuk bertemu teman serta keluarga. Dengan demikian dapat dikatakan bahwa FWA cenderung memberikan kemudahan bagi karyawan dalam mengatur jadwal kerja dan sosial mereka.

Peneliti berasumsi karyawan yang memiliki FWA dapat membagi waktunya untuk pekerjaan ataupun kepentingan lain. Hal demikian membuat FWA semakin menarik. Kita bisa katakan alasan calon karyawan cenderung memilih FWA ialah karena mereka melihat bahwa FWA merupakan salah satu bentuk kepedualian organisasi terhadap karyawan (Grover \& Crooker, 1995), serta untuk memfasilitasi kemampuan pengaturan yang berbeda-beda karyawan dalam memenuhi tuntutan pekerjaannya. Namun disisi lain beberapa peneliti menyebutkan bahwa fleksibilitas pekerjaan itu tidak memberikan keuntungan untuk dilakukan. Stavrou (2005) melaporkan hubungan negatif antara pola kerja yang tidak standar (termasuk waktu kerja, paruh waktu, pembagian kerja) dan turnover di sektor swasta. Naquin dkk (2010) menunjukkan bahwa orang lebih mau berbohong ketika berkomunikasi melalui email dibandingkan ketika berkomunikasi melalui pena dan kertas. Hal ini diduga karena tidak adanya pengaturan dan pengawasan langsung dari atasan. Falk \& Ichino (2006) menjelaskan tidak adanya pengawasan secara langsung dari perusahaan dapat mengakibatkan menurunnya motivasi instrinsik dan munculnya perilaku tidak etis. PascualEzama dkk (2015) menambahkan kurangnya pengawasan dari perusahaan dapat berakibat munculnya perilaku tidak etis. Karenanya, peneliti ingin melihat apakah perilaku tidak etis cenderung dapat terjadi bila karyawan bekerja dengan fleksibilitas.

Pada banyak studi, Ethical Decision Making tidak hanya dipengaruhi adanya faktor situasional namun juga faktor individu. Deshpande (1996) merekomendasikan agar penelitian ke depan dapat menguji dampak kepuasan kerja dan komitmen organisasi terhadap perilaku etis. Berdasarkan variabel yang telah dibuktikan oleh Ford dan Richardson (1994) dan Loe dkk (2000), penelitian masih belum memasukkan kepuasan kerja 
sebagai faktor pribadi yang relevan untuk pengambilan keputusan etis. Peneliti mengharapkan kepuasan kerja memengaruhi niat pengambilan keputusan yang etis sejalan dengan penelitian yang telah dilakukan Paolillo dan Vittel (2002).

Kepuasan kerja menurut Robbins dan Judge (2015) adalah perasaan positif tentang pekerjaan yang dihasilkan dari suatu evaluasi dari karakteristikkarakteristiknya. Tingkat kepuasan kerja sangat beragam, tergantung pada aspek apa yang diukur misalnya pekerjaan itu sendiri, gaji, promosi, rekan kerja atau keselurahannya. Karyawan yang lebih puas, mereka lebih menyukai apa yang mereka inginkan dan mencari otonomi sendiri (Scotlland dkk, 2005). Yetmar dan Eastman (2000) juga menemukan bahwa dua variabel yang terkait dengan pengalaman orang-orang dengan pekerjaan mereka konflik peran dan kepuasan kerja memengaruhi kesadaran moral, dengan peran konflik yang dikaitkan secara negatif dan kepuasan kerja berhubungan positif dengan sensitivitas etika.

Gambar 1. Bagan Hipotesis dalam Penelitian ini
Studi yang dilakukan oleh Yetmar dan Eastman (2000) menemukan bahwa kepuasan kerja, serta keadaan yang mempengaruhi, secara positif terkait dengan sensitivitas etika. Hal ini didukung pula oleh penelitian Mantel (2005), di mana ia menemukan bahwa ketika peserta memiliki pengaruh positif, mereka lebih cenderung membuat keputusan etis daripada ketika pengaruh mereka netral. Mantel berpendapat bahwa pengaruh positif membuat karyawan memikirkan keputusan mereka lebih teliti, dan dengan demikian membuat keputusan yang lebih etis. Namun hal ini tidak konsisten dengan penelitian lain. Ambady \& Gray (2002), misalnya, menjelaskan bahwa suasana hati yang positif akan kurang terkait erat dengan penilaian dan keputusan yang baik (keputusan etis), pemrosesan yang lebih rumit dapat menyebabkan penilaian dan keputusan yang kurang akurat dalam keadaan tertentu. Dari latar belakang tersebut maka penelitian ini akan melihat apakah kepuasan kerja memediasi hubungan flexible work arrangement dengan ethical decision making"

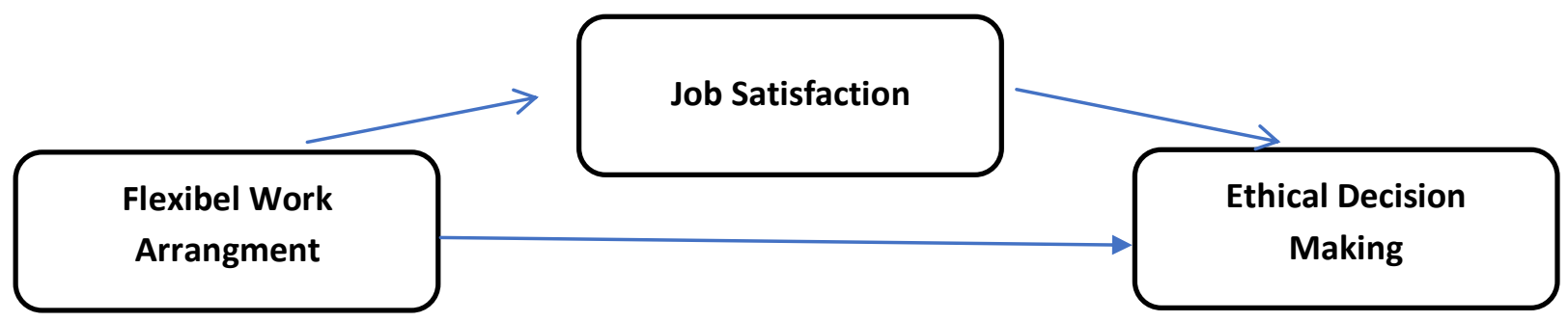




\section{METODE}

Metode penelitian yang digunakan adalah kuantitatif. Sampel dalam penelitian ini adalah mereka yang telah bekerja di Indonesia. Teknik pengambilan sampel dilakukan secara acak (simple random sampling) sehingga setiap individu memiliki kesempatan yang sama besar untuk dipilih sebagai sampel penelitian.

Peneliti memberikan link SurveyMonkey kepada partisipan untuk diisi. Kuesioner online disebar melalui media WhatsApp kepada partisipan lalu kemudian disebarkan lagi ke grup WhatsApp maupun media virtual lainnya. Dari hasil penyebaran, terdapat 700 kuesioner yang terisi. Namun hanya 375 kuesioner yang sesuai dengan kriteria dan dapat dianalisis. Dimana terdiri dari laki-laki sebanyak 173 orang $(46,1 \%)$ dan 222 perempuan (53.9\%). Penggolongan usia partisipan $74,6 \%$ partisipan berada di rentang usia 19-40 tahun, 19,9\% partisipan berada direntang usia 31-50 tahun dan 5,5\% partisipan berada di rentang usia 51-65 tahun.

Sebelum melakukan pilot study, peneliti melakukan beberapa langkah yang komprehensif dalam menerjemahkan, mengadaptasi dan memvalidasi skala kepada beberapa penerjemah (Sousa \& Rojjanasrirat, 2011). Hal ini dilakukan untuk memastikan bahwa alat ukur yang digunakan ini layak untuk diuji coba. Untuk menguji hipotesis menggunakan model 4 mediation melalui program PROCESS untuk SPSS.

Peneliti mengukur kepuasan kerja dengan menggunakan skala Hoppock (1935) yang terdiri dari empat pertanyaan pilihan ganda, dengan tujuh pilihan jawaban. Untuk mengukur fleksibilitas kerja menggunakan Flexible Work-Home Questionnaire yang merupakan adaptasi dari skala Ten Brink (2004) terdiri dari 3 item dengan 5 bentuk pilihan jawaban. Skala Ethical Decision Making disusun berdasarkan pendekatan etika yang dikembangkan oleh Fraser (2007) terdiri dari 19 item mengenai persepsi individu terhadap EDM. Realibilitas dari skala kepuasan kerja adalah 0,73, skala Ethical Decision Making 0,82 serta skala fleksibilitas kerja 0,92 .

\section{HASIL DAN PEMBAHASAN}

Untuk menguji hipotesis yaitu penerapan FWA berhubungan positif dengan tingkat EDM individu melalui mediasi kepuasaan kerja dilakukan analisis menggunakan PROCESS untuk SPSS versi 22.0. Peneliti menggunakan model 4 mediation dengan tingkat kepercayaan (confidence interval - CI) $95 \%$ dengan estimasi 5,000 bootstrap sampel. Hasil analisis dapat dilihat dalam Tabel 1 yang menunjukkan bahwa FWA berpengaruh positif terhadap JS $(\mathrm{SE}=0.90,95 \%$ CI $[0.25,0.59] \mathrm{p}<0.05)$. Pada Tabel 1 dapat dilihat juga bahwa JS 
berpengaruh positif terhadap tingkat EDM

$(\mathrm{SE}=0.101,95 \% \mathrm{CI}[-0.488,-0.090]$.

Tabel 1 Hasil Analisis Mediation

\begin{tabular}{lccclllccccc}
\hline & \multicolumn{4}{c}{ JS (Mediator) } & \multicolumn{4}{c}{ EDM (DV) } \\
\cline { 2 - 11 } & $\mathbf{t}$ & SE & $\mathbf{p}$ & LLCI & ULCI & $\mathbf{t}$ & SE & $\mathbf{p}$ & LLCI & ULCI \\
\hline FWA & 4.74 & 0.90 & 0.00 & 0.25 & 0.59 & 3.50 & 0.21 & 0.00 & 0.33 & 1.16 \\
JS & & & & & & 3.43 & 0.12 & 0.00 & 0.18 & 0.65 \\
\hline
\end{tabular}

Hasil penelitian pengaruh flexible work arrangement terhadap pengambilan keputusan etis adalah positif dan signifikan $\mathrm{F}$ $(1,373)=22,28, \mathrm{p}<.01, \mathrm{R}^{2}=.06$. Pengaruh flexible work arrangement dan kepuasan kerja terhadap pengambilan keputusan etis adalah positif dan signifikan $\mathrm{F}(2,372)=$ 15,$79 ; \mathrm{P}<.01 \mathrm{R}^{2}=.08$.

Dari hasil analisis di atas, nilai efek tidak langsung tidak terstandar bootstrap sebesar 0,17, dan interval kepercayaan (CI) 95\% berkisar antara 0,05 sampai 0,32. Karena nol tidak termasuk dalam rentang interval kepercayaan 95\%, maka dapat ditarik kesimpulan bahwa terdapat efek tidak langsung yang signifikan flexible work arrangement terhadap ethical decicion making melalui kepuasaan kerja.

\section{PEMBAHASAN}

Hasil penelitian ini menunjukkan bahwa terdapat hubungan yang positif antara flexible work arrangement terhadap ethical decision making. Hal ini terjadi karena komponen-komponen intensitas moral yang mendasari tahapan proses EDM terjadi pada karyawan yang menerapkan flexibility work arrangement. Proses EDM menurut Rest (1986) terdiri dari 4 tahap, yaitu moral awareness, moral judgment, moral intention, serta moral action. Karyawan yang dihadapkan pada flexibility work arrangement akan melakukan pertimbangan pada setiap konsekuensi, dan menentukan keputusan yang paling tepat secara moral, supaya dapat mengimplementasikan keputusan yang etis. Hal ini juga dapat dikarenakan karyawan bertindak berdasarkan kode etik dan standar profesionalisme dalam bidang pekerjaannya (Miner \& Petocz, 2003).

Dalam studi ini ditemukan pula bahwa kepuasan kerja dapat memediasi hubungan antara flexibility work arrangement terhadap ethical decision making. Dalam hubungan ini, kepuasaan kerja yang berkualitas tinggi dari situasi pekerjaan yang fleksibel, akan mempengaruhi sikap dan tingkah laku karyawan dalam bekerja. Hasibuan (2007) menjelaskan bahwa kepuasan kerja adalah 
sikap yang menyenangkan dan mencintai pekerjaannya. Sikap ini dicerminkan oleh moral kerja, kedisiplinan, dan prestasi kerja. Maka dari itu, hal inilah yang mendasari ethical decision making pada karyawan semakin tinggi sesuai dengan Mantel (2005) yang berpendapat bahwa pengaruh positif membuat karyawan memikirkan keputusan mereka lebih teliti, dan dengan demikian membuat keputusan yang lebih etis.

Penelitian tentang pengambilan keputusan etis di Indonesia juga masih didominasi oleh penelitian bisnis yang terfokus pada auditor sehingga penelitian selanjutnya sejalan dengan topik ini masih perlu untuk diteliti terutama pada bidang ilmu lainnya. Penelitian ini berbentuk penelitian survey dengan desain cross sectional, sehingga tidak ada kesimpulan mengenai arah hubungan kausal di antara variabel tersebut (Shklovski dkk, 2004). Penelitian lanjutan bisa dilakukan dengan menambahkan variabel-variabel yang terkait dengan ethical decision making secara lebih kompleks dengan menggunakan skenario etika ataupun vignette.

\section{SIMPULAN DAN SARAN}

Berdasarkan hasil penelitian dapat disimpulkan bahwa penerapan Flexible work arrangment mempengaruhi ethical decision making. Penerapan FWA berhubungan positif dengan tingkat EDM pada individu di dalam organisasi melalui kepuasaan kerja. Jadi semakin tinggi penerapan flexible work arrangement pada anggota organisasi akan semakin besar kepuasaan kerja pada karyawan maka semakin etis pula pengambilan keputusan yang mereka pilih.

\section{DAFTAR RUJUKAN}

Ambady, N., \& Gray, H.M. (2002). On being sad and mistaken: Mood effects on the accuracy of thin-slice judgments. Journal of Personality and Social Psychology, 83, 947-961.

Annel, K. \& Hartmann. (2007). Flexible Work Arrangements in Asia : What companies are doing, why they are doing it and what lies ahead. Boston College Center for Work \& Family

Barnett, T. (2001). Dimensions of moral intensity and ethical decision making: An empirical study. Journal of Applied Social Psychology, 31, 1038- 1057.

Deshpande, S. P. (1996). Ethical climate and the link between success and ethical behavior: An empirical investigation of a non-profit organization. Journal of Business Ethics, 15, 315-320

Duhita, Sattwika. (2018, April). Tren Jam Kerja Fleksibel Bikin Anak Muda Lupa Kalau Lembur Harusnya Dibayar. Vice, diunduh dari https://www.vice.com/id_id/article/8xk dbv/tren-jam-kerja-fleksibel-bikinanak-muda-makin-lupa-kalau-lemburharusnya-dibayar

Falk, A., \& Ichino, A. (2006). Clean Evidence on Peer Effects. Journal of Labor Economics, 24(1), 39-57

Ford, R.C. \& Richardson, W.D. (1994). Ethical Decision Making: A review of 
the Empirical literature. Journal of Business Ethics 13, 205- 221

Golden, T.D., \& Veiga, J.F. (2005). The impact of telecommuting on job satisfaction: resolving inconsistent findings. Journal of management, 31 , 301-318

Grover, S. L., \& Crooker, K. J. (1995). Who appreciates family-responsive human resource policies: The impact of family-friendly policies on the organizational attachment of parents and non-parents. Personnel Psychology, 48, 271-288.

Hasibuan, Malayu S.P 2007. Manajemen Sumber Daya Manusia Perusahaan. Bandung, PT. Bumi Aksa.

Hobfoll,S.E.(1989).Conservation resources:A new attemptat conceptualizing stress. American Psychologist, 44, 513-524.

Hoppock, R. (1935). Job Satisfaction. New York. NY: Harper.

Jones, T. M. (1991). Ethical decision making by individuals in organizations: An issuecontingent model. Academy of Management, 16, 366-395.

Kohlberg, L. (1976). Moral Stages and Moralization: The CognitiveDevelopment Approach. In T.Lickona (Ed.), Moral development and behavior: Theory, research and social issues: 31-53.

Loe, T. W., Ferrell, L., \& Mansfield, P. (2000). A review of empirical studies assessing ethical decision making in business. Journal of Business Ethics, 25, 185-204.

Mantel, S.P. (2005). Choice or perception: How affect influences ethical choices among salespeople. Journal of Personal Selling \& Sales Management, 25, 43-55.
Miner, M., \& Petocz, A. (2003). Moral Theory in Ethical Decision Making: Problems, Clarifications and Recommendations from a Psychological Perspective. Journal of Business Ethics, 42(1), 11-25.

Naquin, C. E., Kurtzberg, T. R., \& Belkin, L. Y. (2010). The finer points of lying online: E-mail versus pen and paper. The Journal of Applied Psychology, 95, 387-394.

Ongori, H. (2007), A Review of the Literature on Employee Turnover, Africa Journal of Business Management, 1(3): 49-54.

Pascual-Ezama, D., Dunfield, D., Liaño, B. G. G. De, \& Prelec, D. (2015). Peer effects in unethical behavior: Standing or reputation? PLOS ONE, 10(4), 1-14.

Paolillo, J. G. P., \& Vitell, S. J. (2002). An empirical investigation of the influence of selected personal, organizational, and moral intensity factors on ethical decision making. Journal of Business Ethics, 35, 65-74

Rau, B. L., \& Hyland, M. M. (2002). Role conflict and flexible work arrangements: The effects on applicant attraction. Personnel Psychology, 55, 111-136.

Rest, J. R. (1986). Moral Development: Advances in Research and Theory. New York: Praeger.

Robbins, S. P., \& Judge, T. A. (2015). Perilaku Organisasi. Jakarta: Salemba Empat

Shklovski, Irina; Kraut, Robert; dan Rainie, Lee. (2004). "The Internet and Social Participation: Contrasting CrossSectional and Longitudinal Analysis". Journal of Computer-Mediated Communication 10

Sousa, V. D., \& Rojjanasrirat, W. (2010). Translation, adaptation and validation 
of instruments or scales for use in cross-cultural health care research: a clear and userfriendly guideline. Journal of Evolution in Clinical Practice, 268-274.

Stavrou, E. (2005). 'Flexible work bundles and organizational competitiveness: a cross-national study of the European work context', Journal of Organizational Behavior, 26, 923-947

Sukmana, Yoga. (2018, September). Kejagung Tahan Mantan Dirut Pertamina Karen Agustiawan. Kompas, diunduh dari https://nasional.kompas.com/read/2018 /09/24/18524511/kejagung-tahanmantan-dirut-pertamina-karenagustiawan.

Ten-Brink, B. E. H. (2004). Psychological contract: A useful concept? PhD thesis, Kurt Lewin Instituut Vrije Universiteit, Amsterdam

Yetmar, S.A., \& Eastman, K.K. (2000). Tax practitioners' ethical sensitivity: A model and empirical examination. Journal of Business Ethics, 26, 271288. 